\title{
Parents experiencing a perinatal death found that their interactions with social institutions devalued their loss
}

Malacrida C. Complicating mourning: the social economy of perinatal death. Qual Health Res 1999 Jul;9:504-19.

QUESTION: How do parents of infants who die in the perinatal period experience interactions with social institutions related to the death?

\section{Design}

Qualitative analysis of narratives from interviews.

\section{Setting}

Interviews were conducted in 2 large cities, a small town, and several rural communities in 2 provinces in Canada.

\section{Participants}

Parents (16 women and 6 men) who had lost an infant at $\geq 20$ weeks gestational age were recruited through a newspaper advertisement and from 2 bereavement support groups. 16 infants were stillborn, 5 lived for a few hours, and 1 lived for 7.5 days.

\section{Methods}

Semistructured interviews were usually held in the participants' homes. Parents described their interactions with healthcare providers, social workers, funeral directors, insurance agents, clergy, family, and friends. Analysis was both inductive and deductive; data were coded using Rando's model of complicated mourning.

\section{Main findings}

Findings revealed an informal social economy of perinatal death; a lack of overall support suggested to parents that their loss was not serious or valued. Parents reported that the social support received from their families and friends fell short of their expectations. Even the expected gestures of acknowledgment (eg, cards, flowers, and hospital visits) did not occur. Parents interpreted this inattention as an indication that the death was not an important life event. Parents experienced a lack of support from the medical community and other helping professions, beginning with the blunt and uncaring manner in which they learnt that their child had died. Little was done to assuage parents' doubts and guilt about the reasons for the death. Although most parents received a visit from a hospital social worker, it was basically to provide a contact number to call if they had problems. In seeking support and understanding, more than half the parents eventually entered counselling at their own expense. Parents who were involved with their religious community were disappointed at how little material support they received; 4 parents of stillborn children were refused baptisms.

In our society, certification and paperwork represent legitimacy. Parents struggled to have their loss legitimised through legal documentation. They were sometimes discouraged from having birth and death certificates issued. Over half the parents wanted a funeral, but insurance policies did not cover the costs and the ceremonies were poorly attended. Employers were often seen as being unsupportive of parents' needs for paid time off. The overall message was “you can't lose what you never had." This left parents alone to deal with their loss, which contributed to complicated mourning.

\section{Conclusions}

Parents of infants who died in the perinatal period experienced a lack of support from their families, the medical and helping professions, religious communities, and legal and economic institutions. This lack of support was interpreted by parents as a devaluation of their loss and contributed to complicated mourning.

\section{COMMENTARY}

Issues of death and dying are complex. Death of a child in the perinatal period is particularly challenging by virtue of the loss being "invisible." Because the child only lived in utero or for a short time after birth, outsiders may not perceive the death as a significant life event. This study by Malacrida provides vivid documentation of the social interactions parents experience after surviving a late term pregnancy loss or early infant death. The study findings fit well with Rando's model of complicated mourning ${ }^{1}$ and Doka's concept of disenfranchised grief. ${ }^{2}$

By examining parents' interactions in various social spheres, Malacrida gives strong direction for nurses in practice. Her findings reinforce the crucial role of nurses in the care of parents experiencing perinatal loss. Nurses in all clinical areas including perinatal units, emergency departments, surgery wards, and in the community, must communicate openly and listen sensitively to these parents so as to validate their loss.

Malacrida's findings also emphasise the importance of perinatal loss as a family health issue. Through holistic care, nurses can assess and intervene with parents' extended and chosen families. This will strengthen the support parents receive from their closest social networks.

Analysis of grieving parents' interactions with legal and economic institutions is a new area in perinatal loss research. This macro level perspective is essential for nurses to advocate for the needs of these families at the societal level.

This study presents a thorough examination of parents' interactions with many different social institutions after a perinatal loss. It is an important contribution to our understanding of an intensely meaningful, but often marginalising, experience for parents and families.

Hope Schreiber, RN

Clinical Nurse III, Labor and Delivery Southwest Texas Methodist Hospital San Antonio, Texas, USA

1 Rando TA. The increasing prevalence of complicated mourning: the onslaught is just beginning. Omega 1992;26:43-59.

2 Doka KH. Disenfranchised grief. In: KH Doka, editor. Disenfranchised grief:recognizing hidden sorrow. Lexington, MA: Lexington Books, 1998:1-13. 